\title{
Histologia e histoquímica do tubo digestório de Phrynops geoffroanus (Testudines, Chelidae)
}

\author{
Danielle Alcantara VIEIRA-LOPES ${ }^{1, *}$, Aparecida Alves do NASCIMENTO ${ }^{1}$, Armando SALES ${ }^{1}$, Adriana \\ VENTURA $^{1}$, Iara Alves NOVELLI ${ }^{2}$, Bernadete Maria SOUSA ${ }^{3}$ Nadja Lima PINHEIRO ${ }^{1}$ \\ Departamento de Biologia Animal, Universidade Federal Rural do Rio de Janeiro. BR 465, Km 7, CEP: 23890-000, Fone/Fax: +55(21) 2682-1711. Seropédica, \\ Rio de Janeiro,Brasil. cidanasci2@globo.com, asales@ufrrj.br, ventura-ufrrj@hotmail.com, nadja@ism.com.br. \\ * Autor Correspondente: dmjvieira@hotmail.com \\ 2 Núcleo de Pesquisa em Ciências Biológicas, Centro Universitário de Lavras. Rua Padre José Poggel, 506, Centenário, CEP: 37200-000, Fone: +55(35) 3283-2833. \\ Lavras, Minas Gerais, Brasil. iaranovelli27@gmail.com \\ ${ }^{3}$ Departamento de Zoologia, Universidade Federal de Juiz de Fora. Campus Universitário, s/n, Martelos, CEP: 36036-900, Fone: (32) 3229-3215, Fax: (32) 3229-3216. \\ Juiz de Fora, Minas Gerais, Brasil. bernadete.sousa@ufff.edu.br.
}

\section{RESUMO}

Phrynops geoffroanus é o quelônio onívoro com mais ampla distribuição geográfica na América do Sul. Este trabalho descreve a histologia e histoquímica do tubo digestório desta espécie, relacionando as características dos órgãos com seu hábito alimentar. O esôfago, estômago e intestino de quatro espécimes foram fixados em formol $10 \%$ e incluídos em parafina por técnica histológica de rotina. Depois, cortes de $5 \mu \mathrm{m}$ de espessura foram corados com hematoxilina-eosina (HE), ácido periódico de Schiff (PAS) e alcian blue (AB) pH 0.4 e 2.5. O tubo é formado pelas camadas mucosa, submucosa, muscular e adventícia ou serosa. A mucosa do esôfago e do estômago é revestida pelo epitélio simples cilíndrico com células mucossecretoras, onde estão inseridas glândulas intraepiteliais na porção do esôfago e fossetas gástricas desembocando em glândulas no estômago. $\mathrm{O}$ estômago divide-se em anterior, médio e posterior, de acordo com a profundidade das fossetas e a concentraçáo de glândulas gástricas. $\mathrm{O}$ intestino é revestido pelo epitélio simples cilíndrico com borda estriada e células caliciformes e divide-se em anterior e posterior, de acordo com o padráo de dobramentos da mucosa e o número de células caliciformes. Reatividade ao PAS e $\mathrm{AB}$ é observada em todo o tubo. Fibras musculares lisas estão presentes na camada mucosa de todos os segmentos. A camada muscular é formada por duas subcamadas de músculo liso, exceto na porção posterior do estômago. Este estudo ajudará no entendimento da fisiologia digestiva da espécie investigada e fornecerá dados para análises comparativas com outros quelônios.

PALAVRAS CHAVES: Réptil, esôfago, estômago, intestino, células mucossecretoras.

\section{Histology and histochemistry of the digestive tract of Phrynops geoffroanus (Testudines, Chelidae)}

\begin{abstract}
Phrynops geoffroanus is the omnivorous chelonian with widest geographical distribution in South America. This work describes the histology and histochemistry of the digestive tube of this species, to relate the characteristics of these organs to the species' eating habit. The esophagus, stomach and intestine of four specimens were fixed in $10 \%$ formal and embedded in paraffin by routine histological techniques. Afterwards, 5 - $\mu \mathrm{m}$ sections were stained with hematoxylin-eosin (HE), periodic acid-Schiff (PAS) and alcian blue (AB) $\mathrm{pH} 0.4$ and 2.5. The tube is formed by the mucosa, submucosa, muscular and adventitia or serosa layers. The mucosa layer of the esophagus and stomach is lined with a simple cylindrical epithelium with mucus-secreting cells, where are intraepithelial glands inserted in the portion of the esophagus and gastric fossettes emptying into glands in the stomach. The stomach is divided into an anterior, middle and posterior region, according to the depth of the fossettes and the concentration of gastric glands. The intestine is lined by a simple cylindrical epithelium with striated boundaries and goblet cells and is divided into an anterior and posterior regions, according to the pattern of folds of the mucosa layer and the number of goblet cells. Reactivity to PAS and AB is observed in the entire tube. Smooth muscle fibers are present in mucosa layer of all the segments. The muscular layer is formed by two sub-layers of smooth muscle, except for the posterior stomach. This study will help understanding of the digestive physiology of $P$. geoffroanus and provide data for comparative analyzes with other turtles.
\end{abstract}

KEYWORDS: Reptile, esophagus, stomach, intestine, mucous-secreting cells. 


\section{INTRODUÇÃO}

A compreensão dos processos fisiológicos nos vertebrados é essencial para obtenção de dados sobre a biologia das espécies. Os conhecimentos ecológicos e evolutivos são primordiais para um manejo apropriado, atividades de conservaçáo (Souza 2004) e o aprimoramento dos ecossistemas. Sendo assim, esclarecer a morfologia do sistema digestório torna-se fundamental uma vez que este reflete fielmente as pressóes exercidas pelo ambiente sobre o organismo. A adaptação a diferentes nichos ambientais leva a mudanças anatômicas e fisiológicas, principalmente do sistema digestório, entre e dentro das diferentes ordens de répteis (Mitchell e DiazFigueroa 2005).

O cágado-de-barbicha (Phrynops geoffroanus Schweigger, 1812, Testudines, Chelidae) é um quelônio de pequeno porte com ampla distribuição geográfica, sendo encontrado desde a Amazônia, Colômbia, Equador, Peru e Bolívia até o norte da Argentina, Paraguai e Uruguai (Rueda-Almonacid et al. 2007). Este possui hábito onívoro, ingerindo sementes, frutos, peixes e insetos (Fachín-Terán et al. 1995), porém em cativeiro sua dieta é preferencialmente carnívora (Molina 1991).

Muitos estudos já foram desenvolvidos com $P$. geoffroanus (Fachín-Terán et al. 1995; Molina 1991; Ferreira Júnior 2009), mas nada que trate da anatomia microscópica do tubo digestório do animal foi investigado. Informações detalhadas sobre o hábito alimentar deste quelônio, com o intuito de esclarecer fenômenos fisiológicos e patológicos do tubo digestório, são pré-requisitos para a implementação de projetos de manejo e conservação. Além disso, este estudo pode servir de base para outras espécies de quelônios, tendo em vista a carência de estudos com esta vertente. Sendo assim, o conhecimento histológico e histoquímico torna-se potencialmente importante uma vez que se encarrega de esclarecer o arranjo e a morfologia celular do tubo digestório facilitando o entendimento da biologia do animal.

Ao longo do tubo digestório, células mucossecretoras eliminam substâncias que contribuem para a lubrificação dos órgãos, proteção contra degradação proteolítica e inibição de micro-organismos, sendo também importantes na absorção e transporte de macromoléculas através da membrana e na diluição da água ingerida (Filipe e Branfoot 1976). A produção destas mucinas varia de uma espécie para outra e também ao longo do canal alimentar.

O objetivo deste trabalho foi descrever a histologia e a histoquímica de células mucosas dos vários segmentos do tubo alimentar de $P$. geoffroanus, bem como a composição e a distribuição de muco no lúmen do tubo digestório, relacionando a função de cada compartimento do sistema digestório com as propriedades dos mucos por eles produzidos, com a finalidade de produzir informaçóes que possibilitem análises comparativas com outros quelônios.

\section{MATERIAL E MÉTODOS}

No presente estudo foram utilizados quatro espécimes de P. geoffroanus (número do tombo: 565, macho; 567, macho; 568, fêmea; 570, macho), que se encontravam acondicionados em meio líquido (formol 10\%) e depositados na Coleção Herpetológica do Departamento de Zoologia da Universidade Federal de Juiz de Fora (UFJF), MG. No Laboratório de Histologia e Embriologia da UFRRJ, o esôfago, estômago e o intestino de cada exemplar foram clivados em cortes seriados transversais e longitudinais e posteriormente processados por técnica histológica de rotina: desidratação (em uma série de concentração crescente de etanol de $70^{\circ} \mathrm{GL}$ a $100^{\circ} \mathrm{GL}$ ), diafanização em xilol, impregnação e inclusão em parafina para obtenção de cortes histológicos de $5 \mu \mathrm{m}$ de espessura. As lâminas com os fragmentos foram coradas pelas técnicas Hematoxilina-Eosina (HE) e Tricrômico de Gomori (TG), para exame da arquitetura pela microscopia de luz. Para identificação de células mucossecretoras foi realizado o estudo histoquímico através do método do Ácido periódico de Schiff (PAS - Mc Manus, 1948 / glicoproteínas com diol vicinal oxidável e/ou glicogênio) e do Alcian Blue (AB - Lev e Spicer, 1964) com pH 0.4 (glicoproteínas altamente sulfatadas) e com pH 2.5 (glicoproteínas com grupos carboxila - ácido siálico e ácido urônico - e/ou com ésteres sulfatados) para evidenciação de glicosaminoglicanas (GAG’s) neutras e ácidas, respectivamente. Todas as lâminas foram observadas e fotomicrografadas respectivamente com câmera digital (Cybershot DSCW 230, Sony, Tóquio, Japão) acoplada em microscópio (BX 40, Olimpus, Tóquio, Japão).

\section{RESULTADOS}

\section{Histologia}

A parede de todo o tubo digestório de P. geoffroanus, é formada por quatro camadas concêntricas: mucosa, submucosa, muscular e adventícia ou serosa. Uma característica do esôfago de $P$. geoffroanus é a presença de uma camada mucosa com pregas digitiformes, longas e espessas. Revestindo estas pregas nota-se o epitélio simples cilíndrico alto com células secretoras de muco de núcleo basal. Entremeadas no epitélio são observadas glândulas bem definidas, formadas por células claras em disposição semicircular. Na base do epitélio encontra-se a lâmina própria bem vascularizada, constituída por tecido conjuntivo e desprovida de glândulas. Adjacente a esta, existe uma camada denominada muscular da mucosa formada por feixes de fibras de músculo liso em sentido longitudinal. Logo abaixo, a camada submucosa é formada por tecido conjuntivo rico em fibras colágenas com capilares sanguíneos e vasos linfáticos (Figura 1). A camada muscular é composta por duas subcamadas de músculo liso, que em cortes longitudinais apresentam-se como uma subcamada 
interna, longitudinal, e uma externa, circular. Externamente, o esôfago é envolvido por uma adventícia, constituída de tecido conjuntivo e vasos sanguíneos.

Em P. geoffroanus, o estômago é dividido em três regiōes segundo suas peculiaridades: anterior, médio e posterior. Isto porque o estômago da espécie estudada apresenta forma tubular, sem nenhum divertículo ou fundo cego, o qual faz apenas uma curva acentuada para a direita. Na luz do estômago de $P$. geoffroanus existem pregas longitudinais que variam quanto à forma de uma região para a outra. Inicialmente, pregas digitiformes altas e delgadas compóem as regiōes anterior e média. Na última porção do órgão estes dobramentos tornam-se baixos, espaçados e com lâmina própria mais abundante. O epitélio de revestimento da camada mucosa ao longo do estômago é simples, constituído por células cilíndricas mucossecretoras, com núcleos basais. Este epitélio dobra-se formando fossetas que são nitidamente menores na região anterior e média quando comparada com a região posterior. Estas fossetas desembocam em glândulas gástricas nos três segmentos do órgão (Figuras 2, 3 e 4).

Outra característica que demarca a divisão do estômago é a abundância das glândulas gástricas presentes na lâmina própria, regiáo esta formada por tecido conjuntivo frouxo e vasos sanguíneos. Na regiấo anterior, a concentraçáo glandular é baixa (Figura 2), tornando-se mais abundante à medida que se afasta do esôfago. Na porção média o número de glândulas gástricas é alto tornando ínfima a porção de tecido conjuntivo presente na lâmina própria (Figura 3). A porção posterior é marcada por uma diminuição no número destas glândulas (Figura 4). As glândulas gástricas são tubulares, ramificadas,

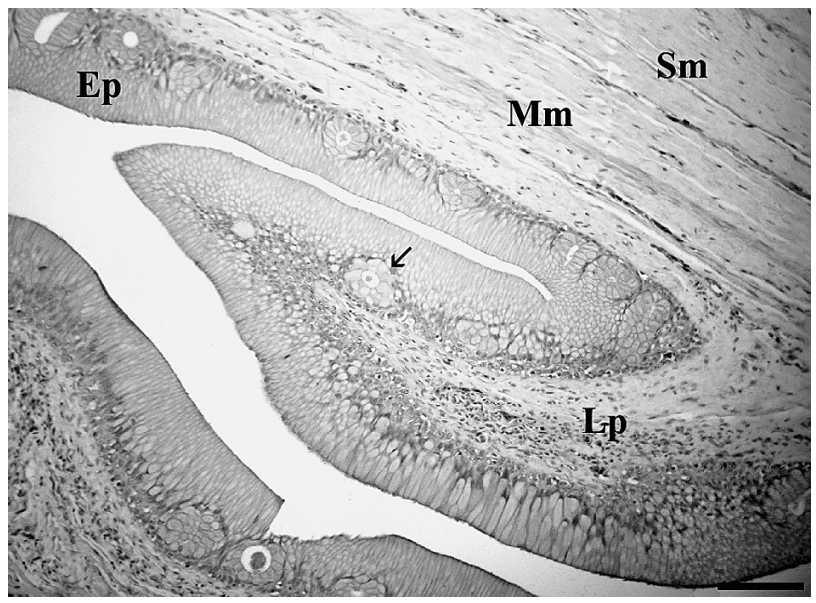

Figura 1- Corte longitudinal do esôfago de $P$. geoffroanus. Mucosa pregueada formada por epitélio simples cilíndrico mucossecretor (indicado por Ep), seguida por lâmina própria vascularizada (indicado por Lp). A seta indica a presença de glândulas intraepiteliais; camada submucosa (indicado por Sm) evidenciada pela presença da camada muscular da mucosa (indicado por Mm) composta por feixes de fibras musculares em sentido longitudinal. Coloração hematoxilina-eosina. Barra $=50 \mu \mathrm{m}$. e formadas principalmente de células escuras oxinticopépticas e células claras mucosas (Figuras 2, 3 e 4). As oxinticopépticas têm formato poliédrico, são acidófilas devido à presença de grânulos de zimogênio (precursores enzimáticos), com núcleo de forma irregular. Estas células desempenham papel semelhante às células principais e parietais em mamíferos, síntese de ácido clorídrico $(\mathrm{HCl})$ e pepsinogênio. As células claras são coradas palidamente pelo $\mathrm{HE}$ e possuem núcleos achatados e situados no polo basal da célula, responsáveis pela produçáo de glicoconjugados.

Separando a camada mucosa da submucosa, observa-se a muscular da mucosa, que na regiáo anterior exibe apenas uma camada de fibras musculares lisas em sentido longitudinal (Figura 2). Nas regiōes média e posterior notam-se fibras musculares em sentidos: circular interno e longitudinal externo (Figura 3). A camada submucosa constitui-se por tecido conjuntivo, vasos sanguíneos e linfáticos.

A camada muscular também é um diferencial para a distinção das regiôes do órgão. As regióes anterior e média exibem feixes de fibras musculares lisas em dois sentidos: circular interna e longitudinal externa. Na primeira região, ambas apresentam a mesma espessura, e na segunda a subcamada circular interna torna-se mais espessa em vista da longitudinal externa. Por fim, na regiáo posterior, a camada muscular expõe feixes de fibras musculares lisas em um único sentido: circular. Intercalando os feixes de fibras musculares desta regiáo notam-se porçôes de tecido conjuntivo frouxo, o que remete a ideia de que a musculatura envolve o tubo de maneira helicoidal. Apenas na regiáo média do estômago observa-se a existência de plexos mioentéricos dispostos em grupos esparsos, compondo o sistema nervoso entérico, entre as subcamadas musculares. Subjacente existe uma camada serosa, constituída de tecido conjuntivo, com algumas fibras nervosas e vasos sanguíneos, revestido pelo mesotélio.

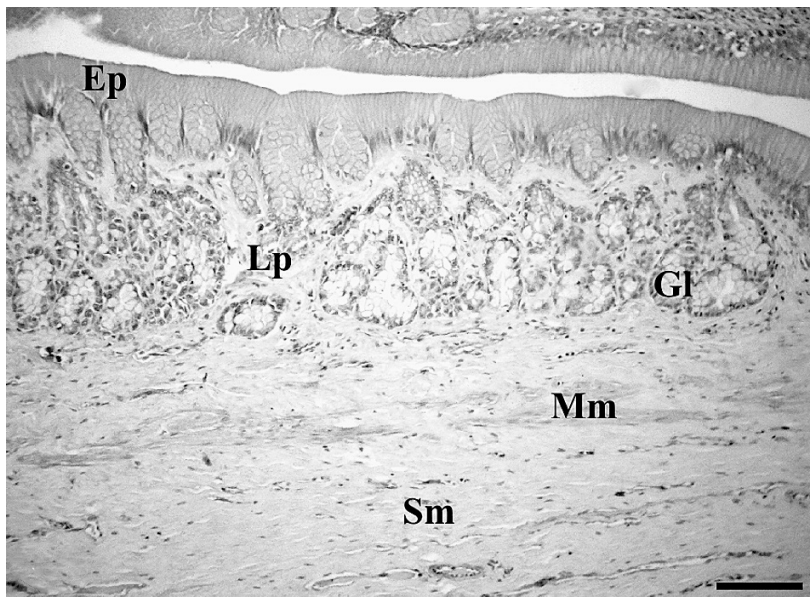

Figura 2- Corte longitudinal do estômago de $P$. geoffroanus. Região anterior - Epitélio gástrico (indicado por Ep), lâmina própria (indicado por Lp) com glândulas gástricas (indicado por Gl) e submucosa (indicado por Sm) evidenciada pela presença da camada muscular da mucosa (indicado por Mm) em sentido longitudinal. Coloração hematoxilina-eosina. Barra $=100 \mu \mathrm{m}$. 


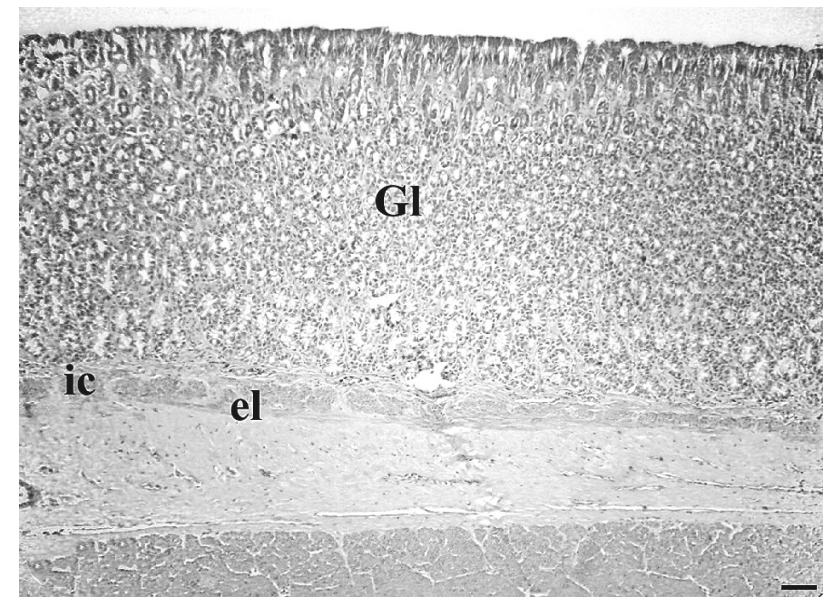

Figura 3- Corte longitudinal do estômago de $P$. geoffroanus. Região média - Maior densidade de glândulas gástricas (indicado por Gl) na lâmina própria tornando ínfima a porção de tecido conjuntivo. Camada muscular da mucosa composta por feixes de fibras musculares em sentidos interno circular (indicado por ic) e externo longitudinal (indicado por el). Coloração hematoxilina-eosina. Barra $=100 \mu \mathrm{m}$.

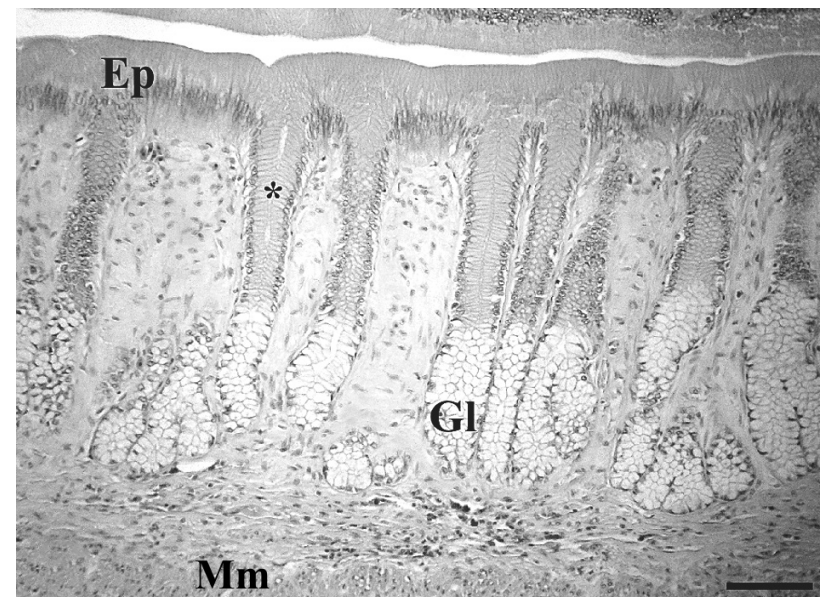

Figura 4- Corte transversal do estômago de P. geoffroanus. Região posterior Asterisco $\left(^{*}\right)$ indicando a presença de fossetas gástricas profundas formadas pelo epitélio, as quais desembocam em glândulas gástricas (indicado por Gl). Camada muscular da mucosa (indicado por $\mathrm{Mm}$ ) presente. Coloração hematoxilina-eosina. Barra $=100 \mu \mathrm{m}$.

Iniciando a caracterização das camadas intestinais, a mucosa é revestida por epitélio simples cilíndrico com borda estriada e células caliciformes (Figuras 5 e 6 ). O tipo celular predominante é o enterócito colunar ou célula de absorção. Células altas, prismáticas, com citoplasma acidófilo e núcleo basófilo situado próximo à base da célula com eucromatina e nucléolo evidente e especializaçáo apical de membrana evidenciada pela borda estriada. Outra célula que também compóe o epitélio é a célula caliciforme, assim denominada por sua forma lembrar a de um cálice, possuindo núcleo deslocado para a porção basal e citoplasma apical pouco acidófilo onde é observada secreção celular.

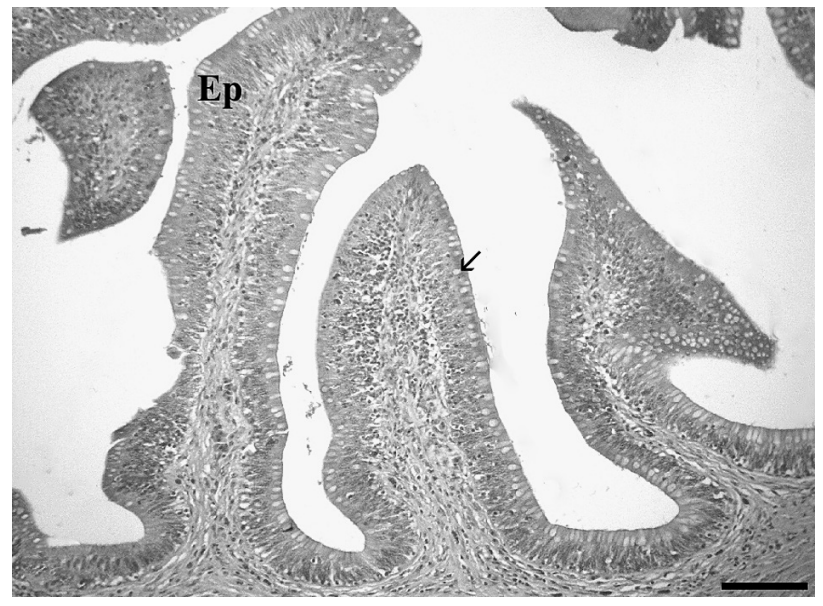

Figura 5- Corte longitudinal do intestino de $P$. geoffroanus. Porção anterior - Visão geral do intestino anterior, mostrando a organização das vilosidades. Detalhe do epitélio simples cilíndrico (indicado por Ep) com borda estriada e células caliciformes. Célula caliciforme indicada pela seta. Coloração hematoxilina-eosina. Barra $=100 \mu \mathrm{m}$.

A camada mucosa é a responsável pela divisão do intestino desta espécie em duas regiōes: intestino anterior e intestino posterior. Uma das características divergentes que permite a divisão do órgão é o número de células caliciformes presentes no epitélio sendo mais abundante na porção posterior quando comparada a porção anterior (Figuras 5 e 6 ). Os cortes em série do intestino anterior demonstram um padrão alternado de vilosidades. Vilosidades digitiformes altas são visualizadas perpendiculares à luz do órgão, as quais por vezes se anastomosam (Figura 5). Em contrapartida observam-se também vilosidades delgadas, longas, em forma de folha, as quais tornam reduzida a luz do órgáo (Figura 7). A altura, frequência e tamanho das vilosidades diminuem à medida que se aproximam da cloaca, tornando-se pregas baixas e espaçadas no intestino posterior (Figura 6).

Outra distinção das regiôes do intestino está relacionada com o comportamento da muscular da mucosa, a qual é formada por feixes de fibras musculares lisas que separam a lâmina própria da submucosa. Na porção anterior, a muscular da mucosa localiza-se na base dos dobramentos intestinais, compostos apenas por epitélio e lâmina própria, o que caracteriza uma vilosidade (Figura 5). Na porção posterior, a mesma acompanha a lâmina própria e a submucosa para dentro do dobramento, caracterizando a estrutura como prega (Figura 6). A camada submucosa é constituída de tecido conjuntivo frouxo com capilares sanguíneos e vasos linfáticos, tornando-se mais espessa ao se aproximar da cloaca. Nenhum indício de glândulas de Lieberkuihn na lâmina própria ou glândulas de Brunner na submucosa é identificado. Observase a presença de infiltrado linfocitário disperso nesta camada.

$\mathrm{Na}$ camada muscular de ambos os segmentos do intestino sáo vistos feixes de fibras musculares lisas que correm em 
sentido circular na parte interna e longitudinal na parte externa, sendo, no entanto, o estrato circular mais desenvolvido. Entre estas subcamadas observa-se tecido conjuntivo frouxo escasso e nele plexos mioentéricos dispersos aleatoriamente na forma de aglomerados e vasos sanguíneos. Adjacente a esta camada encontra-se a serosa, que envolve externamente o órgão, constituída de tecido conjuntivo frouxo, revestido por epitélio simples pavimentoso que repousa sobre uma membrana basal, formando o mesotélio.

\section{Histoquímica}

O epitélio de revestimento de todo o tubo digestório da espécie P. geoffroanus apresenta forte positividade aos métodos do PAS e do $\mathrm{AB}(\mathrm{pH} 0.4 \mathrm{e} \mathrm{pH} \mathrm{2.5),} \mathrm{o} \mathrm{que} \mathrm{indica} \mathrm{a} \mathrm{presença}$

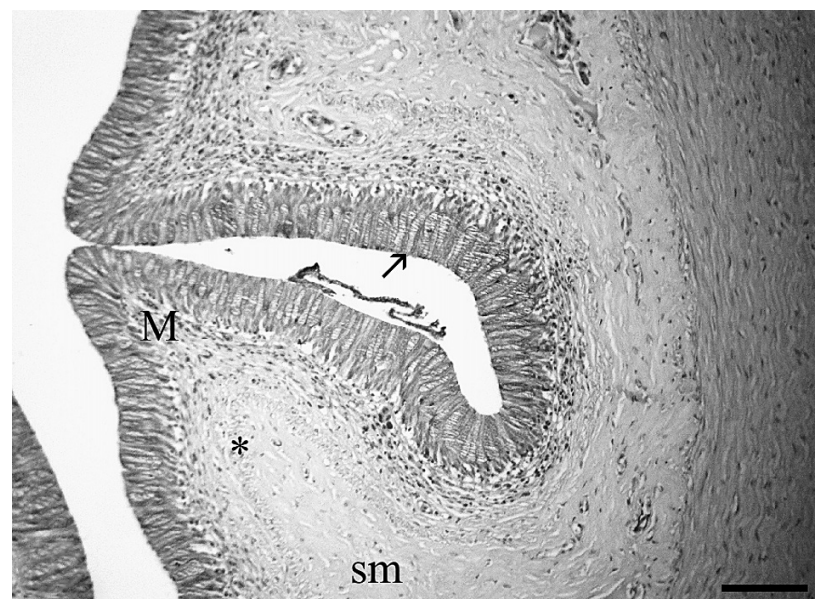

Figura 6- Corte transversal do intestino de $P$. geoffroanus. Porção posterior - Espessamento do epitélio causado pelo elevado número de células caliciformes. Célula caliciforme indicada pela seta. Camada mucosa (indicado por M), junto com a submucosa (indicado por sm) e a camada muscular da mucosa (indicado por asterisco*) formando grandes pregas longitudinais. Coloração hematoxilina-eosina Barra $=100 \mu \mathrm{m}$.

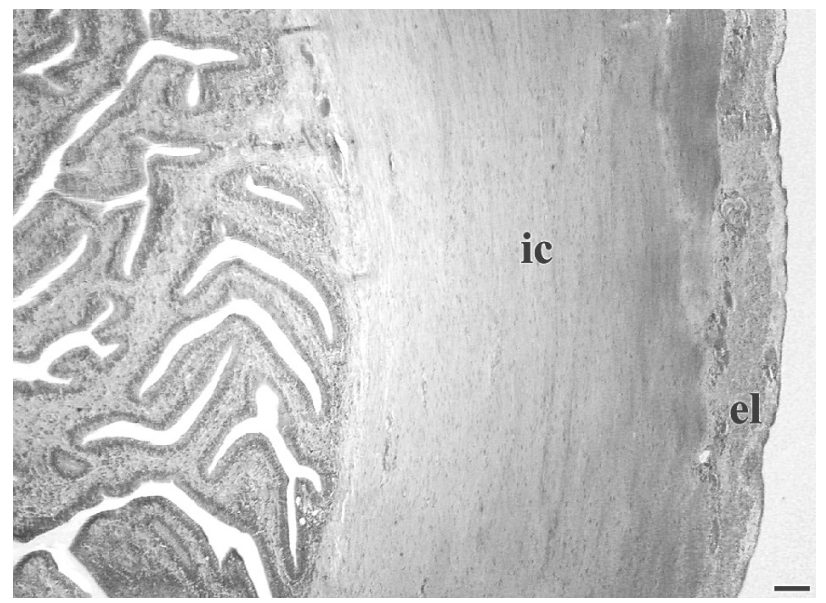

Figura 7- Corte transversal do intestino de $P$. geoffroanus. Porção anterior Camada muscular composta por uma subcamada de fibras musculares lisas interna circular (indicado por ic) e a externa longitudinal (indicado por por el). Coloração hematoxilina-eosina. Barra $=100 \mu \mathrm{m}$. de GAG’’ neutras e ácidas altamente sulfatadas e carboxiladas, respectivamente. As células secretoras que compóem as glândulas intraepiteliais do esôfago também mostram forte reaçâo às técnicas. Já as glândulas gástricas exibem forte positividade ao PAS, sendo decrescente a reatividade ao $A B$ da porção anterior do estômago para a porçáo posterior.

\section{Discussão}

A anatomia dos órgãos do tubo digestório reflete diretamente o tipo de dieta do animal (Stevens e Hume 1998). Anatomicamente o esôfago e o estômago de $P$. geoffroanus apresentam-se como órgãos tubulares, sem saculaçôes, semelhante ao identificado em Mesoclemmys vanderhaegei (Pinheiro et al. 2010), Caretta caretta, Dernochelys coriacea (Magalhães et al. 2012). Répteis carnívoros possuem estômago mais simples se comparados aos herbívoros. Os intestinos possuem comprimentos distintos: um extenso segmento anterior e um curto posterior. Estas dimensóes são geralmente encontradas em carnívoros, sendo o intestino posterior mais longo nos herbívoros (Stevens e Hume 1998), isso porque os alimentos de origem animal são mais facilmente digeridos do que os de origem vegetal. Legler (1993) sugere que os Testudines são oportunistas, aproveitando-se da disponibilidade local de alimento. Isto esclarece o hábito alimentar da espécie como sendo um onívoro oportunista, de acordo com a demanda de alimento, uma vez que segundo Molina (1991), esta espécie em cativeiro possui dieta preferencialmente carnívora. Outra característica que corrobora o fato é a ausência de ceco na junção dos intestinos, porção comum em répteis herbívoros e onívoros (Smith et al. 2001).

A camada mucosa ao longo do tubo digestório de $P$. geoffroanus apresenta numerosos dobramentos longitudinais no sentido do trânsito da ingesta, variando sua forma e sua disposição de um segmento para o outro. A mudança no padrão de dobramentos é fundamental uma vez que, ao aumentar ou diminuir a luz do órgáo controla o trânsito do bolo alimentar. Além disso, denota a ampliação da superfície de absorção (Legler 1993; Wyneken 2001), ou seja, regiōes com pregueamento complexo possuem maior envolvimento nos processos absortivos, e ampliam a capacidade de distensão e acomodaçáo de grandes quantidades de alimentos (Mitchell e Diaz Figueroa 2005).

O epitélio de revestimento do esôfago é do tipo simples cilíndrico com células secretoras de muco, que ocasionalmente formam glândulas pluricelulares, com aspecto mucoso, cuja provável função é lubrificar o órgão. Estas glândulas intraepiteliais também são descritas no jacaré Caiman latirostris (Machado-Santos et al. 2011). Diferente do epitélio esofágico observado na espécie em estudo, em quelônios da família Pelomedusidae (Vogt et al. 1998) o epitélio é do tipo estratificado pavimentoso. Em Egernia kingii (Arena et al. 1990), Alligator mississippiensis (Uriona et al. 2005) 
e C. latirostris (Machado-Santos et al. 2011) o epitélio de revestimento é pseudo-estratificado cilíndrico com células caliciformes. O epitélio pseudo-estratificado cilíndrico ciliado foi registrado no lagarto Tupinambis teguixin e no cágado Hydraspis sp. (Zamith 1952), no lagarto Lacerta lepida (Madrid et al. 1989), na tartaruga Kinosternon scorpioides (Pereira et al. 2005) e na lagartixa Hermidactylus mabouia (Sartori 2009).

Glândulas esofágicas na lâmina própria e na submucosa não foram identificadas em $P$. geoffroanus, esta ausência também é percebida em Mauremys caspica (Madrid et al. 1989), A. mississippiensis (Uriona et al. 2005), C. latirotris (Machado-Santos et al. 2011) e Uromastyx aegyptiaca (Zaher et al. 2012). Já na espécie Testudo graeca (Madrid et al. 1989) estas glândulas foram observadas.

Histologicamente é possível distinguir em quelônios as cavidades do tubo digestório por uma mudança abrupta no epitélio de revestimento, onde o esôfago é revestido pelo epitélio estratificado pavimentoso ou estratificado cilíndrico e passa a estratificado cilíndrico mucossecretor no estômago (Magalhães 2010). Mas em P. geoffroanus, o limite entre estes órgãos não é pontual devido ao epitélio de revestimento ser comum aos órgãos: epitélio simples cilíndrico com células mucossecretoras. A diferenciação das cavidades fica clara devido à existência de glândulas entremeadas no epitélio esofágico e a formação de fossetas gástricas que desembocam em glândulas tubulares na porção do estômago. Esta semelhança entre o epitélio esofágico e o gástrico, descaracteriza a função primordial do esôfago, que é de apenas armazenar e transportar o alimento da cavidade oral para o estômago, e sugere que o esôfago, neste caso, também auxilie na digestão, contrário a ideia de que a digestão inicia-se no estômago (Wyneken 2001; Machado Júnior et al. 2005).

A mucosa do estômago, semelhante à maioria dos vertebrados, é coberta pelo epitélio simples cilíndrico mucossecretor. Dentro da classe dos répteis as espécies K. scorpioides (Pereira et al. 2005) e H. mabouia (Sartori 2009) apresentam este mesmo revestimento no estômago. Outras espécies não apresentam células mucossecretoras, como Varanus niloticus (Ahmed et al. 2009) e U. aegyptiaca (Zaher $e t$ al. 2012). Para estes autores a provável função das secreçôes mucosa é resguardar as células epiteliais contra o ácido clorídrico produzido pelas glândulas gástricas, permitir o trânsito do alimento ao intestino e auxiliar na hidratação do bolo alimentar.

Ao longo de toda a extensão do estômago são observadas fossetas gástricas, ou seja, invaginaçôes do epitélio de revestimento, as quais se comunicam com glândulas tubulares bem desenvolvidas. Estas apresentam variaçóes em sua profundidade entre as porçôes do estômago. $\mathrm{O}$ número de glândulas gástricas na lâmina própria também é diferente entre as regióes. O mesmo é visualizado para as espécies Podocnemis sextuberculata, Peltocephalus dumerilianus e Chelonia mydas, mas difere do observado em P. expansa, Podocnemis unifilis e Podocnemis erythrocephala (Magalhães 2010). O aumento no tamanho das fossetas em direção a porção posterior do estômago pode ser justificada com o concomitante aumento do número de glândulas gástricas, garantido ao alimento contado mais duradouro com as secreçôes eliminadas nesta câmara.

As células oxinticopépticas que compóem as glândulas gástricas, correspondentes às células parietais e principais dos mamíferos, cuja função é de secretar tanto ácido clorídrico $(\mathrm{HCl})$ quanto pepsinogênio, não aparecem apenas nas glândulas gástricas dos répteis, mas também em outros vertebrados não mamíferos. De acordo com Ferri et al. (1999), exibir dois tipos ou um único tipo de células para a síntese de $\mathrm{HCl}$ e pepsinogênio não está ligado à filogenia das espécies.

Já o revestimento intestinal é simples cilíndrico com borda estriada e células caliciformes, o que justifica o papel absortivo dos intestinos. Epitélio similar é descrito no intestino do lagarto $V$. niloticus (Ahmed et al, 2009) da família Podocnemididae (Magalhães 2010) e do C. yacare (Aleixo et al. 2011). Uma das características divergente dos intestinos refere-se ao número de células caliciformes presentes no epitélio, o qual se apresenta mais abundante na porção posterior quando comparada com a porção anterior. Resultado semelhante é visualizado em integrantes da família Podocnemididae (Magalhães 2010). $\mathrm{O}$ produto destas células assegura a lubrificação do tubo e o aprisionamento das partículas a serem eliminadas, viabilizando o deslizamento do bolo alimentar (Filipe e Branfoot 1976; Sibbing e Uribe 1985). A lâmina própria e a submucosa dos intestinos mostram-se aglandulares, condiçáo visualizada em Podocnemididae (Magalháes 2010), C. yacare (Aleixo et al. 2011) e $U$. aegyptiaca (Zaher et al. 2012). Glândulas intestinais são identificadas pela invaginaçáo do epitélio na lâmina própria, padrão nítido na tartaruga verde (Magalhães et al. 2010).

A muscular da mucosa formada por feixes de fibras musculares lisas é observada em todos os segmentos do tubo digestório, seguindo padrôes distintos em cada regiâo. Chaves e Vazzoler (1984) e Santos et al. (2007) admitem que a existência de tecido muscular entre a lâmina própria e a submucosa auxilia na eliminaçáo das substâncias produzidas pelas glândulas, fato comprovado pelo maior espessamento desta camada nas regióes com maior concentração glandular. Esta musculatura é encontrada no esôfago de $K$. scorpioides (Pereira et al. 2005), H. mabouia (Sartori 2009), C. latirostris (Machado-Santos et al. 2011) e U. aegyptiaca (Zaher et al. 2012), sendo inexistente ou ínfima em alguns quelônios (Magalhães 2010); no estômago de H. mabouia (Sartori 2009), C. mydas (Magalháes et al. 2010) e U. aegyptiaca (Zaher et al. 2012); e no intestino de H. mabouia (Sartori 2009) e C. mydas, 
(Magalhães et al. 2010). Vale ressaltar que para P. geoffroanus, na porção posterior do intestino esta musculatura ajuda na formação das pregas longitudinais, o que garante a mobilidade das mesmas, auxiliando no peristaltismo para eliminação dos resíduos alimentares, recurso visualizado no duodeno de $C$. yacare (Aleixo et al. 2011).

A estrutura da camada muscular também apresenta diferenças de uma área para outra no tubo digestório. A camada muscular do esôfago é formada por fibras musculares lisas longitudinais internas e circulares externas, diferente de K. scorpioides (Pereira et al. 2005), H. mabouia (Sartori 2009), C. mydas (Magalhães et al. 2010), C. latirostris (MachadoSantos et al. 2011) e U.aegyptiaca (Zaher et al. 2012). As porçóes anterior e média do estômago constituem-se de uma subcamada circular interna e uma longitudinal externa, padrão semelhante ao visualizado nas espécies $V$. niloticus (Ahmed et al. 2009), C. mydas (Magalháes et al. 2010) e U. aegyptiaca (Zaher et al. 2012). A porção posterior do estômago exibe apenas uma subcamada circular, semelhante ao encontrado ao longo do estômago de H. mabouia (Sartori 2009). Os intestinos voltam à configuração do estômago anterior e médio, semelhante aos répteis H. mabouia (Sartori 2009) e C. mydas (Magalháes et al. 2010). Esta camada é responsável por dar mobilidade ao tubo digestório, transportando e misturando os alimentos com as secreçôes digestivas. Outro tecido que garante este processo é o plexo mioentérico, localizado entre as subcamadas de tecido muscular da regiáo média do estômago, descrito também para H. mabouia (Sartori 2009).

Protocolos histoquímicos de PAS e AB ( $\mathrm{pH} 0.4$ e $\mathrm{pH} 2.5$ ) revelam a produção de GAG's neutras, ácidas sulfatadas e ácidas carboxiladas, respectivamente, em todo o comprimento tubo digestório do cágado-de-barbicha. A primeira, por formar um muco pouco viscoso, atua na constituição de um fluxo laminar durante a lubrificaçáo e o tratamento de partículas, permitindo que o alimento seja transferido de um órgáo para outro; protege os segmentos contra lesóes mecânicas causadas pelo atrito dos alimentos; resguarda a mucosa contra agressores químicos, físicos e biológicos; cria um obstáculo que modifica a passagem de solutos pelo epitélio (Filipe e Branfoot 1976); além de auxiliar na hidratação do bolo alimentar (Magalhães 2010). Já as GAG’s ácidas por possuírem alta viscosidade são fundamentais no aprisionamento de partículas (Sibbing e Uribe 1985). São observadas reaçôes positivas a estes protocolos nos epitélios do tubo digestório de outros répteis como A. mississippiensis (Uriona et al. 2005), H. mabouia (Sartori 2009), V. niloticus (Ahmed et al. 2009), C. latirostris (Machado-Santos et al. 2011) e de U. aegyptiaca (Zaher et al. 2012). Reação apenas ao PAS é observada nas espécies $L$. lepida (Madrid et al. 1989), Podarcis sicula (Ferri e Liquori 1992), Chalcides chalcides (Ferri et al. 1999), K. scorpioides (Pereira et al. 2005) e U. aegyptiaca (Zaher et al. 2012).

\section{CONCLUSÕES}

O estudo histológico e histoquímico do tubo digestório de P. geoffroanus revela padróes de hábito alimentar carnívoro, ou seja, estômago simples glandular, intestino posterior curto, ausência de ceco, produção de mucossecreçóes ao longo do tubo digestório, não possuindo nenhuma especialização para digestão de matéria orgânica vegetal, o que caracteriza a espécie como sendo onívora oportunista. Este estudo vai ajudar no entendimento da fisiologia digestiva da espécie investigada e fornecer dados histológicos a serem usados como referência à compreensão de alteraçóes histopatológicas que possam afetar o sistema digestório de quelônios, facilitando o manejo das espécies. Além disso, permitirão análises comparativas dentro do grupo, fornecendo subsídios para estudos evolutivos futuros.

\section{AGRADECIMENTOS}

Agradecimentos à técnica de laboratório Ilza Lucas Coelho Meirelles por sua assistência e dedicação, ao departamento de Zoologia da Universidade Federal de Juiz de Fora, por ter cedido os espécimes para o estudo e à Coordenação de Aperfeiçoamento de Pessoal de Nível Superior (CAPES) pelo apoio do programa de bolsas.

\section{BIBLIOGRAFIA CITADA}

Ahmed, Y.A.; El-Hafez, A.A. E.; Zayed, A. E. 2009. Histological and histochemical studies on the oesophagus, stomach and small intestines of Varanus niloticus. Journal of Veterinary Anatomy, 2: 35-48.

Aleixo, V.M.; Pressinoti, L.N.; Campos, D.V.S.; MenezesAleixo, R.C.; Ferraz, R.H.S. 2011. Histologia, histoquímica e histometria do intestino de jacaré-do-pantanal criado em cativeiro. Pesquisa Veterinária Brasileira, 31: 1120-1128.

Arena, P.C.; Richardson, K.C.; Yamada, J. 1990. An immunohistochemical study of endocrine cells of the alimentary tract of the king's skink (Egernia kingii). Journal of Anatomy, 170: 73-85.

Chaves, P.T.C.; Vazzoler, C. 1984. Aspectos biológicos de peixes anatômicos. III. Anatomia microscópica do esôfago, estômago e cecos pilóricos de Semaprochilodus insignis (Characiformes: Prochilodontidae). Acta Amazonica, 14: 343-353.

Fachín-Terán, A.; Vogt, R.C.; Gomez, M.F.S. 1995. Food habits of an assemblage of five species of turtles in the Rio Guaporé, Rondônia, Brazil. Journal of Herpetology, 29: 536-547.

Ferreira Júnior, P.D. 2009. Aspectos ecológicos da determinação sexual em tartarugas. Acta Amazonica, 39: 139-154.

Ferri, D.; Liquori, G.E. 1992. Characterization of secretory cell glycoconjugates in the alimentary tract of the ruin lizard (Podarcis sicula campestris De Betta) by means of lectin histochemistry. Acta Histochemica, 93: 341-349.

Ferri, D.; Liquori, G.E.; Scillitani, G. 1999. Morphological and histochemical variations of mucous and oxynticopeptic cells in 
the stomach of the seps, Chalcides chalcides (Linnaeus, 1758). Journal of Anatomy, 194: 71-77.

Filipe, M.I.; Branfoot, A.C. 1976. Mucin histochemistry of colon. Current topics in pathology, 63: 143-178.

Legler, J.M. 1993. Morphology and physiology of the chelonian. In: Glasby, C.J.; Ross, G.J.B.; Beesley, P.L. (Ed.). Fauna of Austrália, Anfibia and Reptilia v.2A.Australian Government Publishing Service, Canberra, p. 42-152.

Machado Júnior, A.A.N.; Sousa, A.L.; Carvalho, M.A.M.; Santos, F.C.F.; Alves, F.R. 2005. Anatomia do fígado e vias bilíferas do muçuã (Kinosternon scorpioides). Archives of Veterinary Science, 10: 125-133.

Machado-Santos, C.; Zeca, S.G.; Abidu-Figueiredo, M.; Ribeiro, I.C.A.; Sales, A. 2011. The esophagus of the crocodilian Caiman latirostris (Reptilia, Crocodylia): histological, histochemical and immunohistochemical study. Journal of Morphological Science, 28: 113-119.

Madrid J.F.; Ballesta, J.; Pastor, L.M.; Perez-Tomas, R.; Hernandez, F. 1989. Distribuition of mucins in the mucosa of the digestive tract of reptiles: a histochemical study. Acta Histochemica, 85: 117-129.

Magalhães, M.S. 2010. Morfologia do tubo digestório aplicada à compreensão da dieta em quelônios da família Podocnemididae. Dissertação de Mestrado - Instituto Nacional de Pesquisas da Amazônia/Fundação Universidade do Amazonas, Manaus, Amazonas. 78p.

Magalhães, M.S.; Freitas, M.L.; Silva, N.B.; Moura, C.E.B. 2010. Morfologia do tubo digestório da tartaruga verde (Chelonia mydas). Pesquisa Veterinária Brasileira, 30: 676-684.

Magalhães, M.S.; Santos, A.J.B.; Silva, N.B.; Moura, C.E.B. 2012. Anatomy of the digestive tube of sea turtles (Reptilia: Testudines). Zoologia, 29: 70-76.

Mitchell, M.A.; Diaz-Figueroa, O. 2005. Clinical reptile gastroenterology. In: Ritzman T.K. (eds.) The Veterinary Clinics of North America Exotic Animal Practice-Gastroenterology. WB Saunders Company, Philadelphia, p.277-298.

Molina, F.B. 1991. Observaçôes sobre os hábitos e o comportamento alimentar de Phrynops geoffroanus (Schweigger, 1812) em cativeiro (Reptilia, Testudines, Chelidae). Revista Brasileira de Zoologia, 7: 319-326.

Pereira, J.G.; Fonseca, C.C.; Menin, E.; Neves, M.T.D. 2005. Estudo histológico e histoquímico do esôfago do muçuã Kinosternon scorpioides Linnaeus, 1766 Reptilia, Chelonia, Kinosternidae). Arquivos de Ciências Veterinárias e Zoologia UNIPAR, 8 : 3-10.

Pinheiro, J.N.; Godoy, I.; Brito, E.S.; Strüssmann, C.; Ferraz, R.H.S. 2010. Macroscopic aspects of the gastrointestinal tract of the south american freshwater turtle Mesoclemmys vanderhaegei (Bour, 1973). Brazilian Journal of Veterinary Research and Animal Science, 47: 429-438.
Rueda-Almonacid, J.V.; Carr, J.L.; Mittermeier, R. A.; Rodriguezmahecha, J. V.; Mast, R. B.; Vogt, R. C.; Rhodin, A. G. J.; Ossavelasquez, J.; Rueda, J. N.; Mittermeier, C. G. 2007. Las tortugas y los crocodilianos de los países andinos del Trópico. Conservación Internacional, Bogotá, 2007, 537p.

Santos, C.M.; Duarte, S.; Souza, T.G.L.; Ribeiro, T.P.; Sales, A.; Araújo, F. G. 2007. Histologia e caracterização histoquímica do tubo gastrintestinal de Pimelodus maculatus (Pimelodidae, Siluriformes) no reservatório de Funil, Rio de Janeiro, Brasil. Iheringia, Série Zoológica, 97: 411-417.

Sartori, S.S.R. 2009. Morfologia do tubo digestive da lagartixa Hemidactylus mabouia Moreau de Jonnès, 1818 (Squamata:Gekkonidae). Tese de Doutorado, Universidade Federal de Viçosa, Viçosa, Minas Gerais. 98p.

Schweigger, A.F. 1812. Prodromus monographiae cheloniorum. Ko"nigsberg. Schweigger 1812 Archives Naturwissenschaften Mathematiks, 1:271-368.

Sibbing, F. A.; Uribe, R. 1985. Regional specialisation in the oropharyngeal wall and food processing in carp (Cyprinus carpio L.). Netherlands Journal of Zoology, 35: 377-422.

Smith, D.; Dobson, H.; Spence, E. 2001. Gastrointestinal studies in the green iguana: technique and reference values. Veterinary Radiology and Ultrasound, 42: 515-520.

Souza, F.L. 2004. Uma revisão sobre padróes de atividade, reprodução e alimentação de cágados brasileiros (Testudines, Chelidae). Phyllomedusa, 3: 15-27.

Stevens, C.E.; Hume, I.D. 1998. Contribuitions of microbes in vertebrate gastrointestinal tract to production and conservation of nutrients. Physiological Reviews, 78: 393-427.

Uriona, T. J.; Farmer, C.G.; Dazely, J.; Clayton, F.; Moore, J. 2005. Structure and function of the esophagus of the american alligator (Alligator mississippiensis). The Journal of Experimental Biology, 208: 3047-3053.

Vogt, R.C.; Sever, D. M.; Moreira, G. 1998. Esophageal papillae in Pelomedusid turtles. Journal of Herpetology, 32: 279-282.

Wyneken, J. 2001. The anatomy of sea turtles. U.S. Department of Commerce NOAA Technical Memorandum NMFSSEFSC-470, 172p.

Zaher, M.; El-Ghareeb, A.W.; Hamdi, H.; Essa, A.; Lahsik, S. 2012. Anatomical, histological and histochemical adaptations of the reptilian alimentary canal to their food habits: I. Uromastyx aegyptiaca. Life Science Journal, 9: 84-104.

Zamith, A. P. L. 1952: Contribuição para o conhecimento da estrutura da mucosa do esôfago dos vertebrados. Anais da Escola Superior de Agricultura Luiz de Queiroz, 9: 359-434.

Recebido em 23/10/2012

Aceito em 19/04/2013 